\title{
The Constant-Stress, Constant-Heating-Rate Test: A Novel Method for Characterizing Transient Mechanical Behavior of Metallic Materials
}

\author{
S.L. SEMIATIN, P.N. FAGIN, N.C. LEVKULICH, B.T. GOCKEL, B.F. ANTOLOVICH, \\ E.M. CRIST, J. CORMIER, and J.S. TILEY
}

\begin{abstract}
A novel mechanical test for characterizing the transient, on-heating mechanical behavior of metallic structural materials was developed. It comprises the continuous heating of a specimen at a constant rate while loaded under a constant true stress. Key features of the approach consist of quantifying the thermal expansion ("thermal compliance") and mechanical compliance of the load train, modeling the plastic flow and onset of localized necking of the test specimen, and the simulation of concurrent phase changes for multi-phase alloys. From such experiments and analyses, the instantaneous, true plastic strain and strain rate as a function of temperature can readily be determined and used to establish constitutive parameters (such as the apparent activation energy, $Q_{\mathrm{app}}$, for plastic flow) and temperatures at which rapid deformation may occur. The test technique was validated for three alloys, Ti-7Al, Ti-6Al-2Sn-4Zr-2Mo-0.1Si (Ti6242S), and superalloy 718. For the single-phase- $\alpha$ titanium alloy, Ti-7Al, semi-log plots of strain rate $v s$ inverse temperature $(\ln \dot{\varepsilon} v s 1 / T)$ were linear, and yielded a value of $Q_{\text {app }}$ comparable to that for self diffusion of hcp titanium. The corresponding plots for Ti6242S with either a fully equiaxed or duplex (equiaxed/colony $\alpha$ ) microstructure were also linear, but exhibited higher values of $Q_{\mathrm{app}}$, a finding rationalized using simulations of the kinetics of dissolution of equiaxed $\alpha$ as a function of temperature and the so-called "mechanical contribution" to the activation energy of two-phase alloy systems. Last, $\ln \dot{\varepsilon}-v s-1 / T$ plots of 718 were either linear (in the solution-treated condition) or approximately bilinear (in the solution-treated-and-aged condition). These observations were interpreted with the aid of simulations of precipitation and dissolution of $\gamma^{\prime \prime}$ and $\gamma^{\prime}$ during continuous heating and the retarding effect on straining of a threshold (back) stress associated with the precipitates.
\end{abstract}

https://doi.org/10.1007/s11661-021-06510-3

(C) The Minerals, Metals \& Materials Society and ASM International 2021

\section{INTRODUCTION}

DETERMINATION of the constitutive response of metallic structural materials under either deformation-processing or service conditions frequently relies on mechanical tests performed under nominally-isothermal conditions. Common test techniques include uniaxial tension, uniaxial compression, torsion, smooth- or

S.L. SEMIATIN and J.S. TILEY are with the Materials and Manufacturing Directorate, Air Force Research Laboratory, WrightPatterson Air Force Base, $\mathrm{OH}$ 45433. Contact e-mail: sheldon.semiatin.1@us.af.mil P.N. FAGIN and N.C. LEVKULICH are with UES, Inc., Dayton, $\mathrm{OH}$ 45432. B.T. GOCKEL is with the Aerospace Systems Directorate, Air Force Research Laboratory, Wright-Patterson Air Force Base, OH 45433. B.F. ANTOLOVICH is with ATI Specialty Materials, Monroe, NC 28111. E.M. CRIST is with Howmet Aerospace, Niles, OH 44446. J. CORMIER is with Institut Pprime, UPR CNRS 3346, ISAE-ENSMA, 1 Avenue Clément Ader, BP 40109, 86961 Futuroscope-Chasseneuil Cedex, France.

Manuscript submitted August 12, 2021; accepted October 21, 2021. Article published online November 21, 2021 notched-bar fatigue, and constant-load or constant-stress creep. ${ }^{[1,2]}$ Such approaches provide useful information such as stress-strain curves and ductility metrics as a function of test temperature, strain rate, stress, etc.

Although isothermal tests provide useful outputs for the broad selection of processing parameters and service allowables, it should be realized that real-world conditions often involve temperature transients. In the area of processing, examples include die chill and deformation heating during conventional metalworking operations, rapid cooling during heat-treat quenching, heating and cooling transients during powder-bed additive manufacturing, interfacial frictional heating during solid-state joining processes, etc. ${ }^{[3-11]}$ Thermal transients during service situations include frictional heating associated with the rubbing of rotating machine components, aerodynamic heating during high-speed flight, etc. ${ }^{[1-14]}$ Despite the ubiquity of non-isothermal conditions, however, relatively-little work has been done to quantify plastic-flow behavior in such instances. 
Several exceptions to the scarcity of material-behavior data pertinent to temperature transients include the so-called on-heating (and on-cooling) tests used to obtain flow stress data for metals processing and specialized tests to quantify creep or fatigue behavior under varying temperature/cyclic-loading conditions similar to those postulated for specific service cycles. For the on-heating (on-cooling) tests,${ }^{[15-20]}$ samples are preheated and soaked at some initial temperature to provide a starting equilibrium microstructure, then heated (or cooled) rapidly to a second temperature, and finally deformed, typically in uniaxial tension. By this means, the plastic flow associated with a non-equilibrium microstructure is established and applied for the design of forging, extrusion, etc. processes for two-phase materials such as titanium and nickel-base alloys. Unfortunately, such tests often neglect the details of the heating rate/path and associated phase-transformation mechanisms and kinetics pertinent to the actual process, however. Thus, the utility of the test in quantifying actual mechanical response during processing may be questioned. On heating and on-cooling tests are also employed to obtain various measures of ductility. For example, on-heating experiments comprising the application of a fixed load are often used to determine the so-called nil-ductility temperature as a function of heating rate. ${ }^{[21]}$

In the area of service behavior, various non-isothermal (thermal-mechanical) fatigue machines have been developed (e.g., Reference 22) and used to investigate the effect on damage of temperature and loading cycles which are in-phase or out-of-phase. From such observations, various models of damage evolution have been developed. ${ }^{[22,23]}$ Special test techniques and analyses have also been formulated to interpret the effect of thermal cycling on microstructure evolution (e.g., dissolution, coarsening, re-precipitation of second phases) and associated high-temperature non-isothermal creep response of aerospace materials such as single-crystal superalloys. ${ }^{[24,25]}$

The present work was undertaken to develop and validate a new test technique that can be used to characterize the plastic-flow response (and associated microstructure evolution) of metallic materials during continuous-heating transients such as may occur due to the deformation heating of large workpieces forged in hydraulic presses, the aerodynamic heating of structural components, etc. For this purpose, a modified mechanical test involving tensile loading under conditions of constant true stress and constant heating rate was formulated and applied to several titanium- and nickel-base alloys. Strain- $v s$-time data from such tests provided significant insight into the constitutive response of both single- and two-phase alloys.

\section{MATERIALS AND PROCEDURES}

\section{A. Materials}

A range of materials exhibiting different types of microstructure evolution during transient thermal cycles was selected for the present program. These materials consisted of the single-phase- $\alpha$ titanium alloy $\mathrm{Ti}-7 \mathrm{Al}$, the two-phase $\alpha / \beta$ titanium alloy Ti-6Al-2Sn-4Zr$2 \mathrm{Mo}-0.1 \mathrm{Si}$ (hereafter referred to as Ti6242S), and the $\gamma^{\prime \prime}-\gamma^{\prime}$-strengthened nickel-base superalloy 718 .

The Ti-7Al material was received in the form of a 76.2-mm-diameter induction-skull-melted ingot that had been cast in a graphite mold. Its measured composition (in wt pet) was $7.2 \mathrm{Al}, 0.05 \mathrm{Fe}, 0.08 \mathrm{O}, 0.01 \mathrm{C}, 0.0054 \mathrm{H}$, $<0.01 \mathrm{~N}$, balance titanium. A $140-\mathrm{mm}$-long section of the ingot was turned in a lathe to a diameter of $73.7 \mathrm{~mm}$, preheated at $1255 \mathrm{~K}$, and extruded to a rectangular cross section measuring $34.3 \times 39.9 \mathrm{~mm}^{2}$, corresponding to a reduction of 3.1:1. Following surface conditioning, a 156-mm-long section of the extrudate was flat rolled perpendicular to the extrusion direction to produce a sheet with dimensions of $4.0 \times 173 \times 305 \mathrm{~mm}^{3}$. The rolling parameters comprised a preheat/reheat temperature of $1255 \mathrm{~K}$, reduction per pass of $\sim 5$ pct., and reheat time between passes of 3 minutes. After rolling, the sheet was annealed 24 hours at $1227 \mathrm{~K}$ and finish ground on both sides (to remove surface defects and contamination) to a final thickness of $1.5 \mathrm{~mm}$. The Ti-7Al sheet so produced had a uniform, single-phase, equiaxed- $\alpha$ microstructure with an average grain size of $120 \mu \mathrm{m}$ and a texture whose principal component consisted of basal poles normal to the sheet surface with a maximum intensity of 12 times random (Figure 1).

The Ti6242S program alloy was received as a 36-mm-thick hot-rolled plate with a measured composition (in wt pet) of $5.97 \mathrm{Al}, 1.97 \mathrm{Sn}, 3.99 \mathrm{Zr}, 2.01 \mathrm{Mo}$, $0.089 \mathrm{Si}, 0.03 \mathrm{Fe}, 0.10 \mathrm{O}, 0.002 \mathrm{C}, 0.002 \mathrm{~N}$, balance titanium. Its $\beta$ transus temperature (at which $\alpha+\beta \rightarrow \beta$ ) was $1266 \quad \mathrm{~K}$. Sections measuring $25 \times 101 \times 36 \mathrm{~mm}^{3}$ were cut along both the rolling direction (RD) and transverse direction (TD) of the plate and given a heat treatment of $1239 \mathrm{~K}$ for 1 hour followed by either air cooling (HT-1) or furnace cooling (HT-2). These treatments produced either a duplex structure of equiaxed $\alpha$ particles (average size $\sim 8 \mu \mathrm{m}$ ) in a matrix of secondary (colony) $\alpha$ (Figure 2(a)) or fully-equiaxed- $\alpha$ (average size $\sim 11 \mu \mathrm{m}$ ) in a matrix of $\beta$ (Figure 2(b)), respectively. [In the backscattered-electron (BSE) images shown in Figure 2, $\alpha$ is the darker phase, and $\beta$ is the lighter phase.] The volume fraction of equiaxed $\alpha$ for the two heat treatments was either 0.44 or 0.93 , respectively. The corresponding $\alpha$-phase textures consisted of basal poles near the RD and TD (HT-1, Figure 2(c)) or near the TD and directions between the RD and TD (HT-2, Figure 2(d)). In both instances, the principal texture components exhibited a maximum intensity of $\sim 6$ to 8 times random.

Blanks for mechanical-test specimens were fabricated via electrical-discharge machining (EDM) of $1.5 \mathrm{~mm}$ sheets from locations near the mid-thickness of the original plate; i.e., far from contaminated regions near the free surfaces.

The 718 program material was received as 2.25-mm-thick sheet with a composition (in wt pct) of 17.6 Cr, 19.27 Fe, 4.93 Nb, 0.54 Al, 0.98 Ti, 3.01 Mo, $0.55 \mathrm{Co}, 0.06 \mathrm{C}$, balance Ni. Sections of the sheet were given one of two heat treatments: Super- $\delta$-solvus solution treat + oil quench (denoted as ST), or 

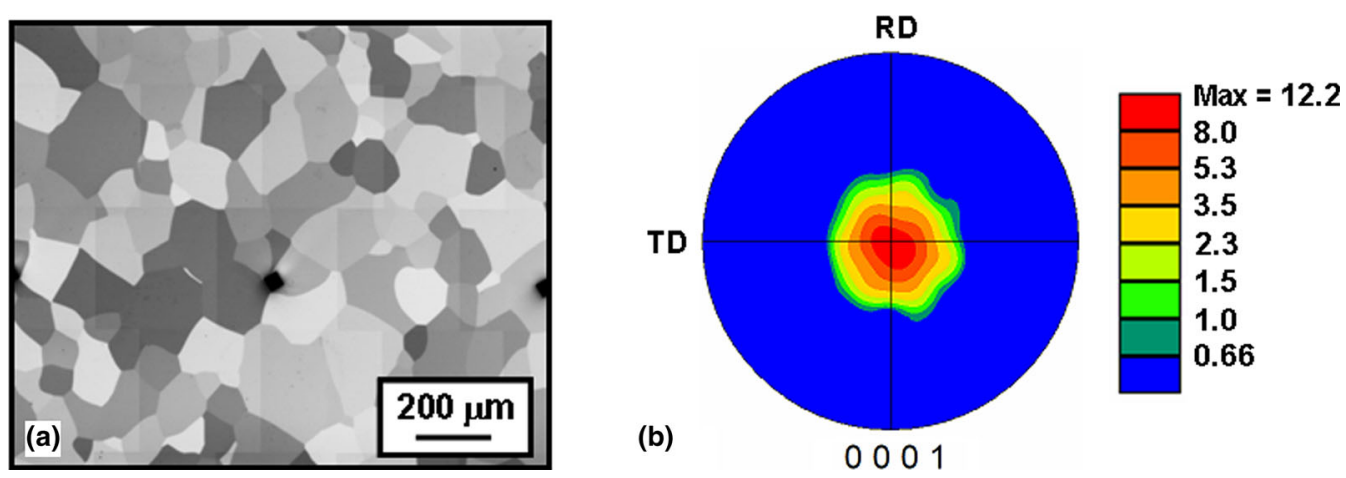

Fig. 1-Ti-7Al program material: (a) Polarized-light optical microstructure and $(b)(0001)_{\alpha}$ pole figure.
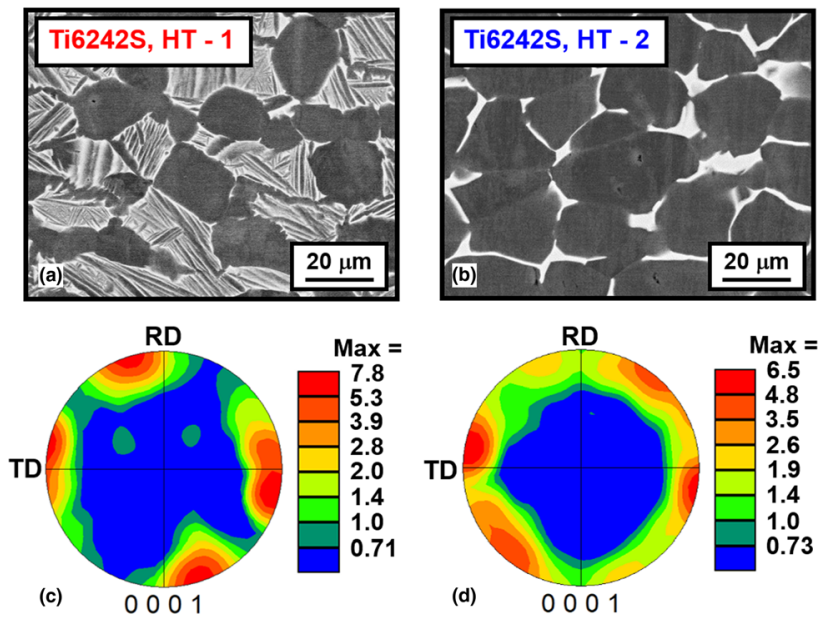

Fig. 2-Ti6242S program material: $(a, b)$ BSE images and $(c, d)$ $(0001)_{\alpha}$ pole figures for material given heat treatments $(a, c)$ HT1 or $(b, d) \mathrm{HT} 2$.

super- $\delta$-solvus solution treat + oil quench + age (STA). In both cases, the super- $\delta$-solvus solution treatment comprised 1 hour at $1339 \mathrm{~K}$. The aging treatment for the STA samples was 8 hours at $993 \mathrm{~K}+8$ hours at $893 \mathrm{~K}+$ air cool. The super- $\delta$-solvus solution treatment gave rise to an average $\gamma$ grain size of $\sim 100 \mu \mathrm{m}$ (BSE image in Figure 3(a)); aging produced distributions of the ordered bct $\left(\mathrm{DO}_{22}\right) \gamma^{\prime \prime}$ and fcc $\left(\mathrm{Ll}_{2}\right) \gamma^{\prime}$ strengthening precipitates with a total volume fraction of 0.15 and average circle-equivalent diameter (CED) of $\sim 11 \mathrm{~nm}$ [secondary-electron (SE) image in Figure 3(b)]. Although no attempt was made to estimate the area fraction or size of each of the two types of precipitates, the oblate nature of $\gamma^{\prime \prime}$ was noted for some particles in the STA samples (Figure 3(b)). After heat treatment, the thickness of each 718 sheet was reduced to $1.5 \mathrm{~mm}$ by grinding equal amounts of material from both plan-view surfaces to eliminate residual contamination.

\section{B. Experimental Procedures}

Constant-true-stress, constant-heating-rate tension tests were performed to establish the constitutive response of the three program alloys under transient
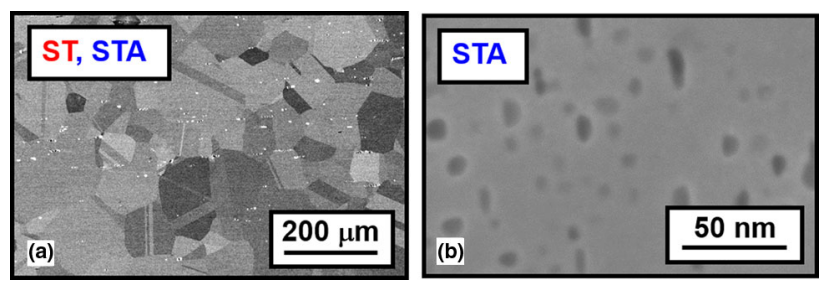

Fig. 3-Superalloy 718 program material: (a) BSE image illustrating the $\gamma$ grain structure developed in both ST and STA samples via super- $\delta$-solvus solution treatment + oil quenching and (b) SE image showing the $\gamma^{\prime \prime} / \gamma^{\prime}$ precipitates developed in STA samples during aging.

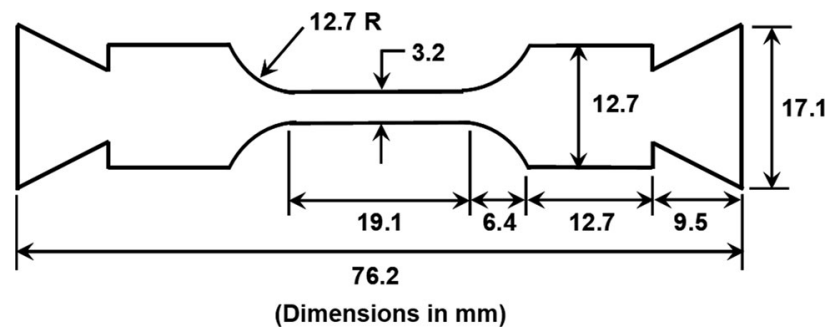

Fig. 4-Geometry of sheet tension specimens used in the present work.

thermal conditions. For this purpose, 1.5-mm-thick sheet samples with a reduced section and overall geometry as shown in Figure 4 were electrical-discharge machined and tested under load/stress-control conditions in a screw-driven mechanical test system. The load train and test fixtures were machined from TZM molybdenum. Sample gripping was effected by friction (plattens along the plan-view surfaces) and mating dovetails (for the tapered edges of each sample). To prevent contamination of the thin sheets and oxidation of the TZM molybdenum tooling, all tests were conducted in an indirect-resistance vacuum furnace (with tungsten-mesh heating elements) that was mounted in the test frame. The hot zone was $\sim 125 \mathrm{~mm}$ long, and the maximum axial temperature variation during heating was $\pm 1.5 \mathrm{~K}$. Temperature was controlled via a thermocouple (Type S for Ti-7Al and Ti6242S, Type $\mathrm{K}$ for 718 ), which was spot welded to the center of the reduced 
section of each sample and enabled a constant heating rate even in the presence of deformation heating or the release/absorption of a latent heat of transformation.

At the beginning of each experiment, the furnace was evacuated to a pressure of $\sim 10^{-6}$ torr. The test sample and load train were then heated to an initial temperature of $810 \mathrm{~K}$ (or $700 \mathrm{~K}$ for selected tests) and soaked for 10 minutes to equilibrate the temperature of the sample and tooling. After the soak period, a load corresponding to a true stress of 175 or $275 \mathrm{MPa}$ (for Ti-7Al), 69 or 103 $\mathrm{MPa}$ (for Ti6242S), or 345 or $483 \mathrm{MPa}$ (for 718) was applied, and heating at a constant rate of 28 or $75 \mathrm{~K} /$ min was begun and continued until failure. During heating, the load was gradually reduced to maintain an approximately-constant axial true stress.

Because of the large imposed strains, high temperatures, and vacuum environment, it was not possible to measure sample deformation using an extensometer attached to the reduced section. The thermal expansion and plastic deformation of the sample and hence the instantaneous cross-sectional area (needed to adjust the load to maintain constant true stress) were estimated based on the thermal and mechanical compliance of the load train and the overall extension measured using an LVDT attached to the test-machine crosshead. The so-called thermal compliance (Figure 5(a)) was determined in preliminary experiments in which the extension of the sample and load-train during continuous heating under a very small axial load (to prevent deformation) was determined. Subtraction of the thermal compliance (at each instantaneous temperature) and the mechanical compliance from the LVDT extension measurement provided the plastic extension imposed on the sample; this plastic deformation was assumed to take place solely within the reduced section of the test sample. Furthermore, at each instant of time, the overall change in cross-sectional area associated with the axial plastic deformation and thermal expansion was determined and used to modify the applied load to maintain a constant axial true stress via a closed-loop control technique. The plot in Figure 5(b) provides a typical example illustrating the extent to which the stress was maintained nearly constant. The sharp drop at the end of the test corresponds to rapid straining during which localized necking and failure occurred.

Following failure, the furnace power was turned off, and the sample cooled to room temperature. Because of the absence of gas or water quenching in the vacuum furnace, a maximum cooling rate of the order of only $\sim 55 \mathrm{~K} / \mathrm{min}$ could be achieved following testing.

Selected isothermal, constant-strain-rate hot tension tests were also performed in the same equipment as that used for the constant-stress, constant-heating-rate experiments. For these trials, samples were heated to a test temperature of either $1089 \mathrm{~K}$ or $1158 \mathrm{~K}$ at a rate of $75 \mathrm{~K} / \mathrm{min}$, soaked for 10 minutes, and then pulled at a constant true strain rate of $0.001 \mathrm{~s}^{-1}$ or $0.005 \mathrm{~s}^{-1}$, respectively, to a true strain of 0.3 .

The microstructures in broken test samples were determined using standard metallographic techniques described previously. ${ }^{[26,27]}$

\section{Data Analysis and Interpretation}

The average axial true plastic strain as a function of time (and hence temperature) was determined from the measured plastic extension ( $=$ LVDT extension thermal compliance - mechanical compliance) and the initial gage length of the sample (at the initial soak temperature). In turn, the axial strain measurements as a function of time and instantaneous temperature were converted to Arrhenius-type plots of $\ln \dot{\varepsilon}$ as a function of inverse temperature $(1 / T)$ to provide insight into the mechanisms of deformation.

For materials with intermediate values of strain rate sensitivity (i.e., $\sim 0.15$ to 0.3 ), substantial quasi-stable flow and the evolution of a diffuse neck occurs following a load maximum in tension. Hence, the evolution of the axial strain profile was quantified. For this purpose, long-wavelength, isothermal flow-localization calculations were performed for the sheet tension test. ${ }^{[28-30]}$ These simulations comprised discretizing the sample geometry into a series of slices along its length and applying the load-equilibrium equation to deduce the strain rate in each slice relative to that in a specific slice. The test material was taken to be strain-rate-hardening

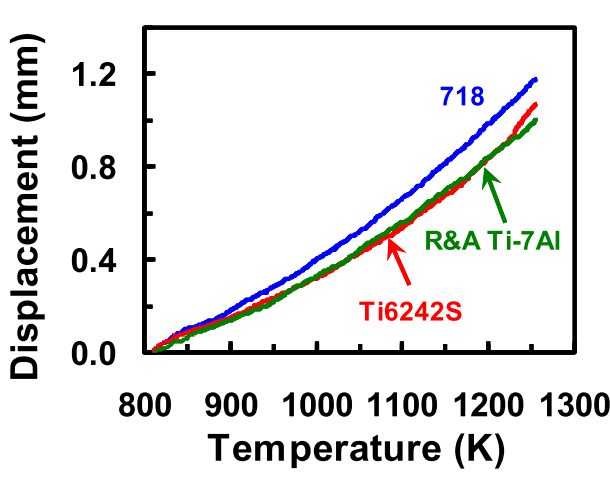

(a)

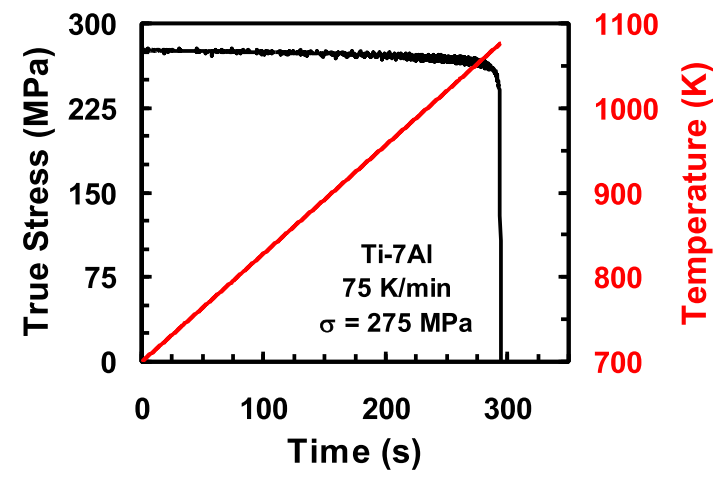

(b)

Fig. 5- Special features of the constant-stress, constant-heating-rate test: (a) Thermal compliance curves for the load train and test samples of each of the program materials and $(b)$ typical test parameters showing stress and temperature as a function of time for a $\mathrm{Ti}-7 \mathrm{Al}$ experiment. 
and non-strain-hardening with a constitutive relation of the form:

$$
\sigma=K\left(\dot{\varepsilon} / \dot{\varepsilon}_{\mathrm{o}}\right)^{m}
$$

where $\sigma, K, \dot{\varepsilon}$, and $\mathrm{m}$ denote the flow stress, strength coefficient, axial strain rate, and rate sensitivity exponent, respectively, and $\dot{\varepsilon}_{\mathrm{o}}$ is a normalization factor for the strain rate. For the present work, the strength coefficient $\mathrm{K}$ was assumed to be 100 (in arbitrary units), and the rate-sensitivity (" $m$ ") was taken to be either 0.15 or 0.30 , or values comparable to those of the program materials. As is usually assumed, ${ }^{[29]}$ the starting sample geometry contained a 1-pct. area defect along its gage length. The boundary condition comprised either a constant true axial stress (relative to a cross-section corresponding to a uniform-deformation approximation, as in the actual experiments) or a constant true average axial strain rate equal to $\dot{\varepsilon}_{\mathrm{O}}$ (relative to the instantaneous sample gage length).

For general non-isothermal cases in which the temperature is increased at a fixed rate, $K$ is a function of temperature and the average strain rate varies as $(\sigma / K)^{1 / m}$. In such instances, the onset of marked flow localization is controlled by the value of $\mathrm{m}$ at the large strains/high temperatures (i.e., the so-called "terminal $m$ "), ${ }^{[30]}$ and isothermal analyses such as that above can still provide useful information on flow uniformity.

Last, the interpretation of transient microstructure evolution and plastic flow for the two-phase materials was facilitated by numerical simulations of precipitation and/or dissolution during continuous heating. The approaches for such simulations were identical to those in prior work for Ti6242S $\mathrm{S}^{[26]}$ and $718 .^{[31]}$

\section{RESULTS AND DISCUSSION}

The principal results of this investigation consisted of the analysis of flow localization during mechanical testing and the measurement and analysis of the plastic-strain- $v s$-temperature data for each of the three program alloys, Ti-7Al, Ti6242S, and superalloy 718.

\section{A. Flow-Uniformity Results}

The nature of the quasi-stable plastic flow during the sheet tension test was quantified by the flow-localization calculations. For a given overall plastic strain, the predicted strain profiles (e.g., Figure 6(a)) were essentially the same irrespective of whether a constant-axial-stress or a constant-axial-strain-rate boundary condition was assumed. This finding was as expected in view of the load-equilibrium formulation of such calculations for which the instantaneous strain rate in any given slice is quantified in terms of that developed in a specific "reference" slice. ${ }^{[28]}$ The strain profiles revealed the typical trend of a delay in the evolution of noticeable flow non-uniformity ( \pm 10 to 15 pct of the average) to higher overall strains with increasing values of the strain-rate sensitivity $(\mathrm{m})$, i.e., strain values equal

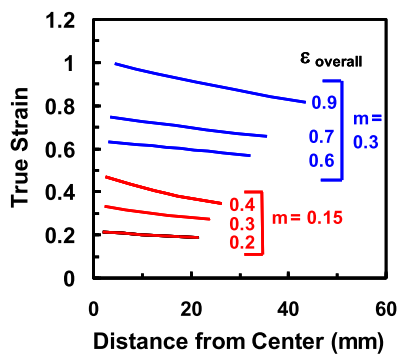

(a)

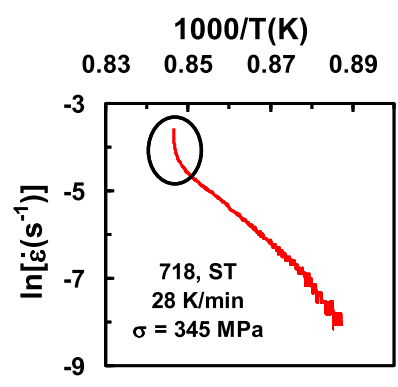

(b)
Fig. 6-Flow localization during sheet tension tests: (a) Simulation predictions of axial strain profiles for $m=0.15$ and $m=0.3$ at various levels of strain and (b) a typical $\ln \dot{\varepsilon}-v s-1 / T$ plot indicating an upturn (circled) corresponding to the onset of rapid flow localization and sample failure.

to or greater than $\sim 0.4$ for $m=0.15$ and $\sim 0.9$ for $m=$ 0.30 .

The strains for noticeable strain non-uniformity deduced from the flow-localization analysis were mirrored by analytical-model predictions of the "limit" strain $\varepsilon_{\mathrm{f}}$ as a function of $\mathrm{m}$ and the size of geometric defect $\left(1-f_{\mathrm{o}}\right),{ }^{[28-30]}$ viz.

$$
\varepsilon_{\mathrm{f}}=-m \ln \left(1-f_{\mathrm{o}}^{1 / m}\right)
$$

For a 1 pct geometric (area-deficiency) defect, $1-f_{\mathrm{o}}$ $=0.01$, and $f_{\mathrm{o}}=0.99$. From Eq. [2], the analytical-model predictions for $m=0.15$ and $m=0.30$ were $\varepsilon_{\mathrm{f}}=0.41$ and 1.02 , respectively.

In view of the flow-localization results, data reduction for the measurements of axial strain as a function of time/temperature (from the constant-stress, constant-heating-rate tests) to obtain $\ln \dot{\varepsilon}-v s-1 / T$ plots focused on overall strains at which the degree of axial strain non-uniformity was estimated to be less than approximately \pm 15 pct. The efficacy of this criterion was corroborated by the $\ln \dot{\varepsilon}-v s-1 / T$ profiles themselves which often revealed a sharp upturn at the onset of rapid flow localization and failure (e.g., circled region in Figure 6(b)).

\section{B. Plastic Flow of $\mathrm{Ti}-7 \mathrm{Al}$}

From a qualitative standpoint, measurements of plastic strain as a function of temperature for $\mathrm{Ti}-7 \mathrm{Al}$ heated at a rate of $75 \mathrm{k} / \mathrm{min}$ (Figure $7(\mathrm{a})$ ) indicated limited deformation at a temperature of $\sim 925 \mathrm{~K}$ and below for imposed stresses of 175 and $275 \mathrm{MPa}$. Above this temperature, straining increased rapidly. Specifically, plastic strains reached 0.02 at temperatures of $\sim 975 \mathrm{~K}$ and $1100 \mathrm{~K}$ for the higher and lower applied stresses. Because of the constant heating rate, plots of plastic strain $v s$ time (not shown) had the same shape as those in Figure 7(a), thus indicating a rapid increase in strain rate with increasing time/temperature.

The dependence of strain rate on temperature became apparent in the corresponding plots of $\ln \dot{\varepsilon}$ as a function 


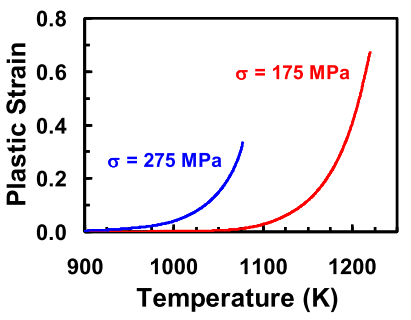

(a)

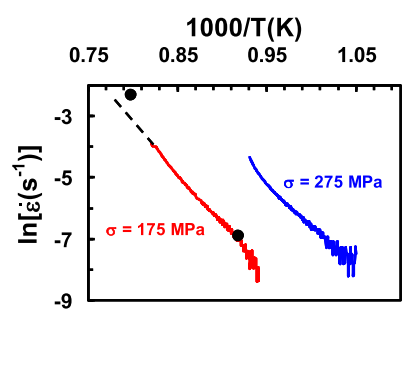

(b)
Fig. 7-Plastic flow of Ti-7Al determined from constant-stress $(\sigma=$ 175 or $275 \mathrm{MPa})$, constant-heating-rate $(75 \mathrm{~K} / \mathrm{min})$ experiments: $(a)$ plastic strain as a function of temperature and $(b) \ln \dot{\varepsilon}$ as a function of $1 / T$.

of the inverse of the absolute temperature $(1 / T)$ (Figure 7(b)). For both stress levels, the dependence was nearly linear. The slopes of such lines were related to an apparent activation energy, $Q_{\mathrm{app}}$, in the often-used (phenomenological) constitutive relation:

$$
\sigma=C \dot{\varepsilon}^{m} \exp \left(\frac{m Q_{\mathrm{app}}}{R T}\right),
$$

in which $C$ is a temperature-independent strength constant, $R$ is the gas constant, and the other symbols are as defined previously. Taking the natural logarithm of both sides of this expression, it is readily found that for the case of a constant stress $\sigma$ and negligible variation of $m$ with $T$ (at least for the temperatures at which the bulk of the deformation occurs), the slope of the resulting straight line on a plot of $\ln \dot{\varepsilon} v s 1 / T$ is equal to $-Q_{\text {app }} / R$. Linear regression fits of the data in Figure 7(b) yielded values of $Q_{\text {app }}$ of 274 or $220 \mathrm{~kJ} / \mathrm{mol}$ for stresses of 175 and $275 \mathrm{MPa}$, respectively (Table I).

The average value of $Q_{\text {app }}$ for the single-phase $\alpha$-titanium alloy Ti-7Al $(247 \mathrm{~kJ} / \mathrm{mol})$ determined herein was comparable to that for self diffusion of $\alpha$ titanium $(300 \mathrm{~kJ} / \mathrm{mol})^{[32]}$ and the $Q_{\text {app }}$ determined from a series of isothermal hot compression tests $(273 \mathrm{~kJ} / \mathrm{mol}) .^{[33]}$ Therefore, the constant-stress, constant-heating-rate test reported here provides a value of $Q_{\text {app }}$ from merely a single experiment. The required single test in the present methodology contrasts with conventional methods of determining $Q_{\text {app }}$ which typically rely on multiple constant-strain-rate isothermal hot-compression tests.

The $\ln \dot{\varepsilon}-v s-1 / T$ results for $\mathrm{Ti}-7 \mathrm{Al}$ were also compared to data for $\sigma=175 \mathrm{MPa}$ derived from isothermal tension or compression tests, shown as solid black circles in Figure 7(b). The lower data point (for $\ln (0.001)$ $=-6.9$ ) came from an isothermal, constant-strain-rate tension test conducted in the present work (Figure 8) in which a flow stress of $\sim 175 \mathrm{MPa}$ was generated by deformation at $1089 \mathrm{~K} / 0.001 \mathrm{~s}^{-1}$. The other data point (for $\ln (0.1)=-2.3$ and $1253 \mathrm{~K}$ ) was estimated from a plot of $\ln \sigma(\varepsilon=0.1)$ vs $1 / T$ for results generated in isothermal, constant-strain-rate compression tests performed at $0.1 \mathrm{~s}^{-1}$ on samples of extruded-and-annealed Ti-7A1. ${ }^{[34]}$ The comparison of the constant-stress, constant-heating-rate data for $\sigma=175 \mathrm{MPa}$ (red line) and
Table I. Apparent Activation Energies, $Q_{\text {app }}$

\begin{tabular}{llcc}
\hline Mat'l & Condition & Stress $(\mathrm{MPa})$ & $\mathrm{Q}_{\text {app }}(\mathrm{kJ} / \mathrm{mol})$ \\
\hline Ti-7Al & Roll+Ann & 175 & 274 \\
Ti-7Al & Roll + Ann & 275 & 220 \\
Ti6242S & HT-1 & 69 & 413 \\
Ti6242S & HT-1 & 103 & 451 \\
Ti6242S & HT-2 & 69 & 408 \\
Ti6242S & HT-2 & 103 & 453 \\
\hline
\end{tabular}

Heating rate $=75 \mathrm{~K} / \mathrm{min}$.

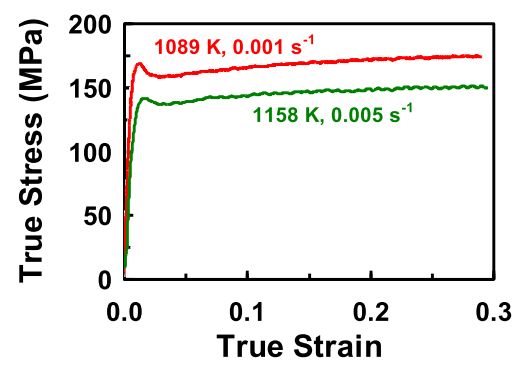

Fig. 8-True stress-true strain curves from isothermal, constant-strain-rate, hot tension tests for Ti-7Al.

isothermal results (black data points) in Figure 7(b) showed moderate to good agreement. Pending further research, the small difference between the (extrapolated) continuous behavior and the compression datum at 0.1 $\mathrm{s}^{-1} / 1253 \mathrm{~K}$ may be hypothesized to have resulted perhaps from variations in strain hardening and/or dynamic recovery associated with the test parameters per se or a temperature/strain-rate-path dependence of plastic flow.

In addition to the apparent activation energy, a value of the strain rate sensitivity $m$ equal to 0.16 was estimated from the strain rates generated in the $\sigma=$ 175 and $\sigma=275 \mathrm{MPa}$ experiments (Figure 7(b)) for $1000 / T=0.95$ corresponding to $T \sim 1050 \mathrm{~K}$ (Table II). This moderately low $\mathrm{m}$ was suggestive of deformation controlled by the glide and climb of dislocations, a behavior in line with observed elongated grain structures in tested samples of this material (Figure 9). The importance of dislocation glide/climb was further underscored by an estimate of the $\mathrm{r}$ value $\left(=d \varepsilon_{\mathrm{W}} / d \varepsilon_{\mathrm{t}} \sim\right.$ $\varepsilon_{\mathrm{w}} / \varepsilon_{\mathrm{t}}$, in which $\varepsilon_{\mathrm{w}}$ and $\varepsilon_{\mathrm{t}}$ denote the width and thickness strains, respectively) determined from measurements at a location $\sim 2.5 \mathrm{~mm}$ from the fracture. For the Ti-7Al alloy, $r$ was $\sim 30$ (Table II). This high $r$ value was indicative of limited thinning arising likely from the sharp basal-normal texture in the extruded-and-rolled sheet material (Figure 1(b)).

\section{Plastic Flow of Ti6242S}

\section{Observations}

The broad behavior of Ti6242S during constant-stress, constant-heating-rate experiments was similar to that of Ti-7Al. For applied stresses of 69 or 103 $\mathrm{MPa}$ and a heating rate of $75 \mathrm{~K} / \mathrm{min}$, for example, plots of plastic strain as a function of temperature exhibited 
Table II. Strain Rate Sensitivities $(m)$ and $r$ Values

\begin{tabular}{llccl}
\hline Mat'l & Condition & Temp $(\mathrm{K})$ & $m$ & $r$ value \\
\hline Ti-7Al & Roll + Ann & 1052 & 0.16 & $\sim 30$ \\
Ti6242S & HT-1 & 1190 & 0.30 & $\sim 0.62$ \\
Ti6242S & HT-2 & 1205 & 0.45 & $\sim 0.48$ \\
718 & ST & 1143 & 0.13 & - \\
718 & STA & 1177 & 0.14 & - \\
\hline
\end{tabular}

Heating rate $=75 \mathrm{~K} / \mathrm{min} ; r$ values estimated from width and thickness strains at a location $\sim 2.5 \mathrm{~mm}$ from fractured end.

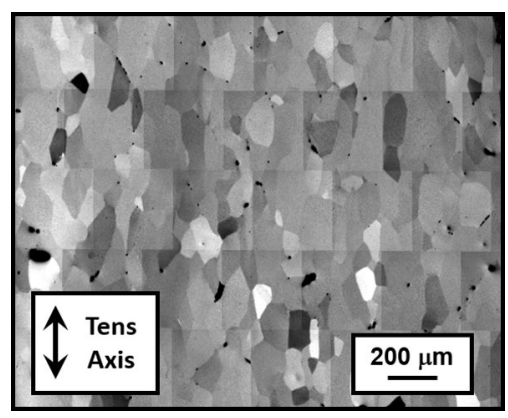

Fig. 9-Polarized-light optical micrograph of a tested Ti-7Al sample $(\sigma=275 \mathrm{MPa}$, heating rate $=75 \mathrm{~K} / \mathrm{min})$ showing the deformed grain structure. The local axial strain was $\sim 0.43$.

minimal deformation below $\sim 1100 \mathrm{~K}$ for both the duplex (equiaxed/colony $\alpha$ ) structure (HT-1) as well as the fully-equiaxed material (HT-2) (Figure 10(a)). At higher temperatures, however, the plastic strain increased in an approximately exponential fashion with increasing temperature. Not surprisingly, the temperature at which noticeable straining began increased with decreasing stress. Furthermore, the equiaxed microstructure appeared to resist marked plastic flow to temperatures slightly higher than those for the duplex structure.

As for the Ti-7Al results, the corresponding $\ln \dot{\varepsilon}^{-}-v s-1 /$ $T$ plots for Ti6242S showed linear behavior for both levels of stress and each microstructural condition (Figure 10(b)). However, the apparent activation energies $\left(Q_{\mathrm{app}}\right)$ deduced from the slopes of these lines, i.e., 410 to $450 \mathrm{~kJ} / \mathrm{mol}$ (Table I), were higher than those for Ti-7Al $(\sim 250 \mathrm{~kJ} / \mathrm{mol})$. Moreover, the values of $Q_{\mathrm{app}}$ for Ti6242S were considerably higher than that for self diffusion in $\alpha$ titanium $\left(\sim 300 \mathrm{~kJ} / \mathrm{mol}^{[32]}\right)$. They were also much higher that the activation energy for impurity diffusion in or hot deformation of $\beta$ titanium (150 to 160 $\left.\mathrm{kJ} / \mathrm{mol}^{[35-37]}\right)$.

\section{Interpretation}

The high values of $Q_{\mathrm{app}}$ for Ti6242S deformed under constant-stress, constant-heating-rate conditions were interpreted in the context of (i) prior measurements of the flow behavior of this alloy under isothermal conditions ${ }^{[38,39]}$ and (ii) a model for the deformation of two-phase microstructures. ${ }^{[40-42]}$ For Ti6242S with an equiaxed- $\alpha$ microstructure, for example, Dadras and Thomas ${ }^{[38]}$ measured the flow stress using isothermal

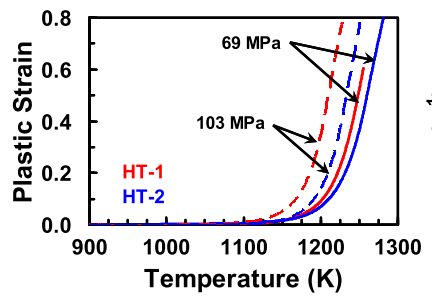

(a)

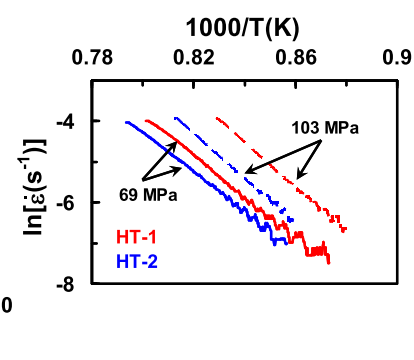

(b)
Fig. 10-Plastic flow of Ti6242S (in each of two different initial heat-treatment conditions) as determined from constant-stress $(\sigma=$ 69 or $103 \mathrm{MPa})$, constant-heating-rate $(75 \mathrm{~K} / \mathrm{min})$ experiments: $(a)$ Plastic strain as a function of temperature and $(b) \ln \dot{\varepsilon}$ as a function of $1 / T$.

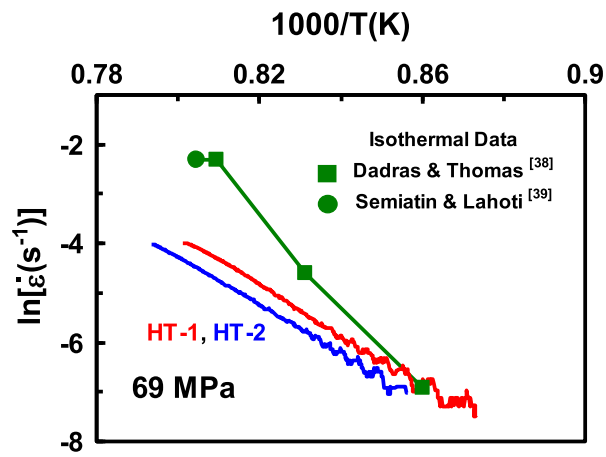

Fig. 11-Comparison of present constant-stress $(\sigma=69 \mathrm{MPa})$, constant-heating-rate $(75 \mathrm{~K} / \mathrm{min}) \ln \dot{\varepsilon}-v s-1 / T$ data for Ti6242S (red, blue lines) with results derived from previously-measured isothermal flow stress data for an equiaxed- $\alpha$ microstructure (green line, data points ${ }^{[38,39]}$ (Color figure online).

hot-compression tests at constant true strain rates of $10^{-3}, 10^{-2}$, or $10^{-1} \mathrm{~s}^{-1}$ and temperatures between 1144 and $1255 \mathrm{~K}$. Denoting $\log \dot{\varepsilon}$ by $X$, they fit their data for $\varepsilon$ $\sim 0.1$ to the following expression:

$$
\log \sigma(\mathrm{MPa})=9.85(1000 / T)-A
$$

in which

$$
A=0.0350 X^{2}-0.109 X+5.992
$$

Hot compression data at $\dot{\varepsilon}=10^{-1} \mathrm{~s}^{-1}$ were also obtained by Semiatin and Lahoti. ${ }^{[39]}$ From these two sets of results, the strain-rate/temperature combinations that produced a flow stress of $69 \mathrm{MPa}$ were determined and compared to the $\ln \dot{\varepsilon}-v s-1 / T$ behaviors obtained from the corresponding constant-stress, constant-heating-rate experiments (Figure 11). The isothermal, hot compression data exhibited a $\ln \dot{\varepsilon}-v_{s}-1 / T$ behavior with a slight curvature. A best straight line fit, however, resulted in $Q_{\text {app }} \sim 720 \mathrm{~kJ} / \mathrm{mol}$, a value substantially greater than that found for the non-isothermal tests conducted in the present work, i.e., 410 to $450 \mathrm{~kJ} / \mathrm{mol}$.

The difference between the activation energies deduced from isothermal-hot-compression and the present continuous-heating data for Ti6242S with an 
equiaxed- $\alpha$ microstructure was explained, at least qualitatively, in terms of the temperature dependence of phase fractions/phase compositions and their influence on the apparent activation energy. As described in the work of Briottet, et al. ${ }^{[40]}$ and others ${ }^{[41,42]}$ such variations give rise to a so-called "mechanical contribution" to the activation energy. In particular, Briottet et al. examined the plastic flow of two-phase microstructures assuming isostrain, isostress, or self-consistent behaviors. The first two of these models yielded analytical expressions for the activation energy. Although the overall flow stress and strain partitioning between the two phases in $\alpha / \beta$ titanium alloys appears to be best described by a self-consistent approach, ${ }^{[26]}$ an analytical expression is not available for this case. By contrast, the isostrain model does not treat non-uniform strain-partitioning between the two phases, but it does predict levels of flow stress similar to those from the self-consistent approach. ${ }^{[26]}$ Moreover, microstructure observations near the fracture sites of failed Ti6242S samples in the present work (Figure 12, HT-2)* suggested that strain differences between primary $\alpha$ and the matrix phase may not have been large. Thus, the analytical expression for the isostrain case was used to interpret

\footnotetext{
*The micrographs in Figure 12 for HT-2 and HT-1 both showed a matrix of un-deformed secondary- $\alpha$ lamellae whose origin was likely a transformation from the high-temperature $\beta$ phase during cooling
} following testing.

the present measurements of $Q_{\mathrm{app}}$.

The isostrain model of Briottet, et al. ${ }^{[40]}$ indicates that the apparent activation energy is the sum of two factors, i.e.,

$$
Q=\frac{f_{\alpha} \sigma_{\alpha} m_{\alpha} Q_{\alpha}+\left(1-f_{\alpha}\right) \sigma_{\beta} m_{\beta} Q_{\beta}}{f_{\alpha} \sigma_{\alpha} m_{\alpha}+\left(1-f_{\alpha}\right) \sigma_{\beta} m_{\beta}}-R T^{2} \frac{\left(\sigma_{\alpha}-\sigma_{\beta}\right)}{m \sigma} \frac{\mathrm{d} f_{\alpha}}{\mathrm{d} T},
$$

where $f_{\alpha}$ denotes the volume fraction of the $\alpha$ phase, $\sigma=f_{\alpha} \sigma_{\alpha}+\left(1-f_{\alpha}\right) \sigma_{\beta}$ is the rule-of-mixtures flow stress, and the subscripts denote properties of the $\alpha$ and $\beta$ phases. The first factor in Eq. [5] is the mixtures-rule expression for the activation energy that would apply if $f_{\alpha}$ is not a function of temperature. The weighting factors in this case are simply the products of the area fraction, flow stress, and rate sensitivity. The second term in Eq. [5] is a "mechanical contribution" which depends on $f_{\alpha}(T)$ as well as the flow stress of each phase and that of the overall aggregate.

To apply Eq. [5] to estimate the two contributions to $Q_{\text {app }}$ for Ti6242S with the HT-2 starting microstructure, it was necessary to quantify $f_{\alpha}(T), \sigma_{\alpha}, \sigma_{\beta}$, etc. In the present work, the diffusion-based dissolution analysis described in Reference 26 was used to estimate $f_{\alpha}(T)$ for a lognormal distribution of spherical equiaxed- $\alpha$ particles with an initial average radius of $5.5 \mu \mathrm{m}$, a heating rate of $75 \mathrm{~K} / \mathrm{min}$, and values of the diffusivity of the rate-controlling solute $(\mathrm{Mo})^{[26]}$ representative of a strain-free $\beta$ matrix ("static case") or a matrix which is undergoing concurrent straining as the temperature is increased ("dynamic case"). Simulation predictions of the temperature dependence of $f_{\alpha}$ during heating at 75 $\mathrm{K} / \mathrm{min}$ indicated moderate differences for the cases without or with concurrent deformation (Figure 13(a)). The predicted value of $f_{\alpha}$ at the final (peak) temperature for the dynamic case was almost identical to the measured volume fraction of primary $\alpha$. Despite the absence of water quenching in the experiments, the source of the good agreement was rationalized on the basis of the development of a solute "trough" (and hence zero-flux location) adjacent to second-phase particles at the onset of cooling following a heating transient. ${ }^{[43]}$ The results in Figure 13(a) also showed that $f_{\alpha}(T)$ for the dynamic on-heating case differed noticeably from the equilibrium (beta-transus approach curve) case (broken line), ${ }^{[4]}$ the latter pertaining to the interpretation of isothermal hot compression data.

The flow stresses of the $\alpha$ and $\beta$ phases, which were also needed to apply Eq. [5], were estimated from (i) the phase compositions as determined from the instantaneous phase fractions predicted in the dissolution analysis or those pertaining to equilibrium conditions and (ii) composition-dependent constitutive relations for each phase. ${ }^{[2,42,44]}$ Last, it was assumed that $m_{\alpha}=m_{\beta}$ $=m=0.25$, based on the measurements of Oikawa and
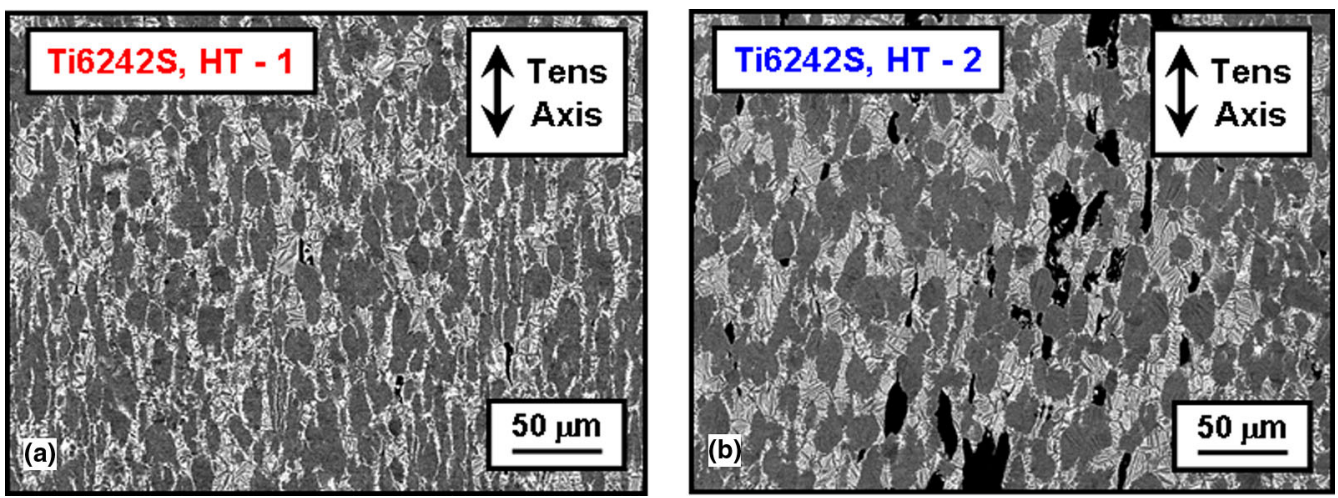

Fig. 12-BSE micrographs taken near the fracture sites of Ti6242S samples with initial microstructures of either $(a)$ HT-1 or $(b)$ HT-2. Test conditions comprised a constant stress $(\sigma=103 \mathrm{MPa})$ and constant heating rate $(75 \mathrm{~K} / \mathrm{min})$. The local axial strains were (a) $\sim 1.6$ or (b) 1.51 . 


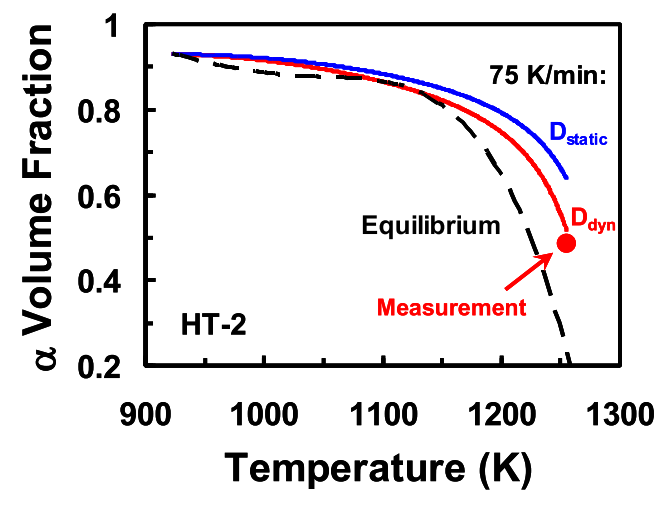

(a)

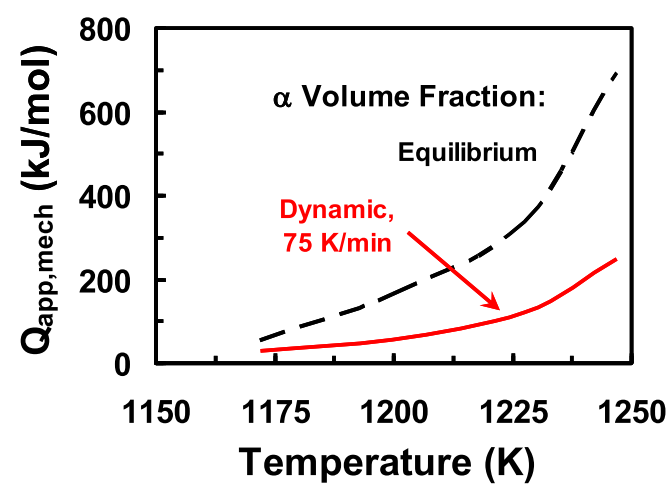

(b)

Fig. 13-Interpretation of the apparent activation energy for Ti6242S from constant-stress, constant-heating rate tests and "equilibrium" isothermal-compression tests in terms of $(a)$ dissolution simulations of the variation of $\alpha$ volume fraction as a function of temperature and $(b)$

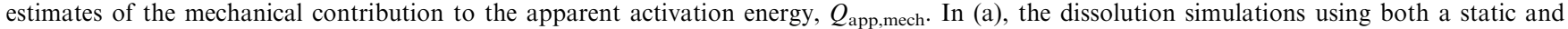
dynamic diffusivity (blue, red curves) are compared to volume fractions corresponding to the equilibrium beta-transus approach curve (broken black line $)^{[44]}$ (Color fgure online).

his co-workers for single-phase- $\alpha$ and single-phase- $\beta$ alloys ${ }^{[33,36,37]}$ and $Q_{\alpha}=300 \mathrm{~kJ} / \mathrm{mol}$ and $Q_{\beta}=160$ $\mathrm{kJ} / \mathrm{mol}$. The assumed value of $\mathrm{m}$ was similar to that measured from the $\ln \dot{\varepsilon}-v s-1 / T$ plots for HT-1 but lower than that for HT-2 (Table II). The higher measured value for HT-2 may have resulted from the onset of near-superplastic conditions as the peak temperature was approached during testing. In support of this inference, approximate $\mathrm{r}$ values for HT-1 and HT-2 were both substantially less than unity (Table II), most likely arising from the basal-transverse textures (Figures 2(c) and (d)) and indicative of deformation by a dislocation glide/climb mechanism.

With the inputs so obtained, the two terms in Eq. [5] were estimated. For temperatures between $1150 \mathrm{~K}$ and $1250 \mathrm{~K}$, the first term in this expression varied relatively little with temperature, being $275 \pm 7 \mathrm{~kJ} / \mathrm{mol}$ for the on-heating/dynamic dissolution case or $258 \pm 23 \mathrm{~kJ} / \mathrm{mol}$ for the isothermal (equilibrium phase fractions/compositions) case. In view of the noticeable difference in the temperature dependence of $f_{\alpha}$ (Figure 13(a)), the second, mechanical, contribution to the activation energy, $Q_{\text {app,mech }}$, showed a much greater divergence for the two cases. Although the estimates did indicate a substantial temperature dependence (Figure 13(b)), the approximate magnitudes of $Q_{\mathrm{app}, \mathrm{mech}}$ were of the order of $125 \mathrm{~kJ} / \mathrm{mol}$ for the on-heating/dynamic case and $\sim 400 \mathrm{~kJ} / \mathrm{mol}$ for the isothermal case. Summing the two contributions, the predicted overall apparent activation energies were thus $\sim 400 \mathrm{~kJ} / \mathrm{mol}$ (on-heating/dynamic case) and $660 \mathrm{~kJ} / \mathrm{mol}$ (isothermal case), or values in qualitative agreement with the measurements, i.e., $430 \mathrm{vs}$ $720 \mathrm{~kJ} / \mathrm{mol}$. Hence, the present approximate analysis suggested that the major source of the difference in $Q_{\text {app }}$ between the two cases was indeed the mechanical contribution. Refinements to the present analysis such as relaxation of the assumptions of isostrain deformation, the equivalence/constancy of the values of the strain-rate sensitivity of each phase, etc would certainly be beneficial in future research. Additional modifications (e.g., deformation/dissolution of Ti6242S with a colony- $\alpha$ matrix) would also be necessary to describe the behavior for the Ti6242S HT1 case.

\section{Plastic Flow of Superalloy 718}

Measurements for superalloy 718 during constant-stress, constant-heating-rate testing showed a noticeable dependence of plastic flow on initial heat-treatment condition (ST vs STA) and heating rate. For instance, typical results for an applied stress of 345 MPa indicated that the shapes of the true-strain- $v s$-temperature curves were different for ST and STA samples (Figure 14(a)). Both sets of data exhibited a noticeable increase in deformation with increasing temperature. However, the curves for the ST samples appeared relatively smooth, suggestive of a gradual transition similar to the behaviors shown by Ti-7Al (Figure 7(a)) and Ti6242S (Figure 10(a)). In addition, measurable straining occurred for ST samples essentially during the onset of heating; this effect was more noticeable for the slower heating rate $(28 \mathrm{~K} / \mathrm{min})$. By contrast, the appearance of the straining transition for STA samples was more abrupt and occurred at higher temperatures for both imposed heating rates. The onset of rapid deformation at higher temperatures for the STA samples might be expected if coherency and, to a lesser extent, order strengthening associated with $\gamma^{\prime \prime}$ precipitates were retained by the STA samples. ${ }^{[45-48]}$

The $\ln \dot{\varepsilon}-v s-1 / T$ curves corresponding to the 718 strain-temperature plots (Figure 14(b)) suggested additional factors that may have affected the transient deformation response. The 718 ST samples showed nearly-linear behavior in such plots, similar to the observations for the other two program alloys. However, the values of $Q_{\mathrm{app}}$ extracted from the average slopes of these lines showed a measurable dependence on heating rate, viz. $510 \mathrm{~kJ} / \mathrm{mol}$ for $75 \mathrm{~K} / \mathrm{min}$ and 755 $\mathrm{kJ} / \mathrm{mol}$ for $28 \mathrm{~K} / \mathrm{min}$. The lower value of $Q_{\mathrm{app}}$ is similar 


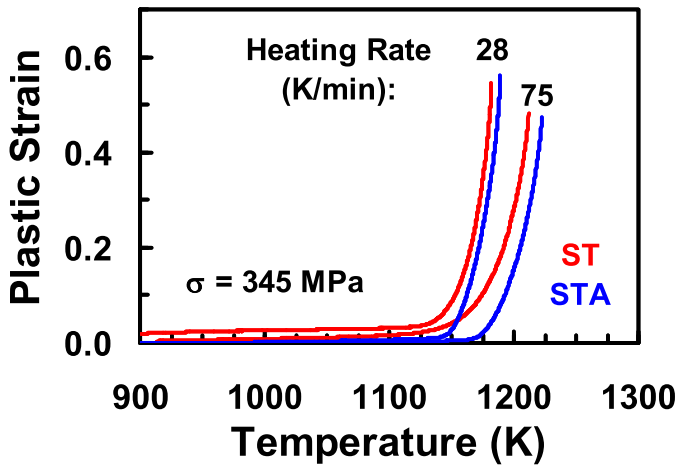

(a)

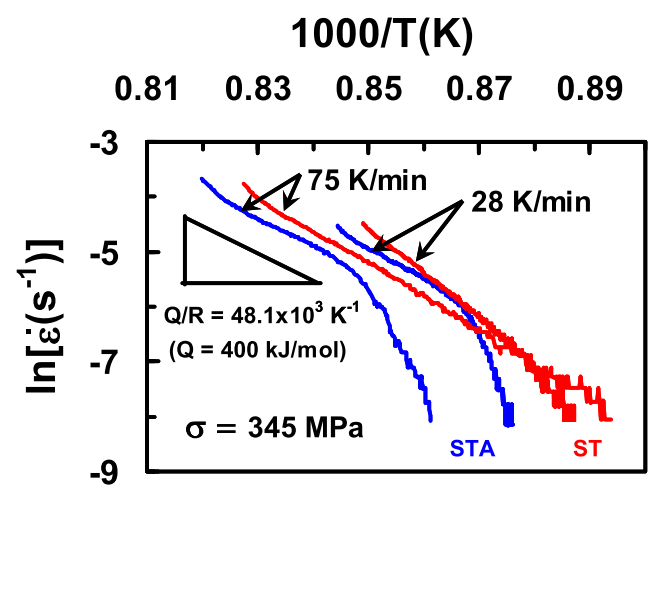

(b)

Fig. 14-Plastic flow of superalloy 718 in an ST or STA condition as determined from constant-stress $(\sigma=345$ MPa), constant-heating-rate $(75$ or $28 \mathrm{~K} / \mathrm{min}$ ) experiments: (a) plastic strain as a function of temperature and $(b) \ln \dot{\varepsilon}$ as a function of $1 / T$.

to, but somewhat higher than, that measured by Zhou and Baker ${ }^{[49]}$ using isothermal hot compression testing conducted at $T=1223$ to $1423 \mathrm{~K}$ and $\dot{\varepsilon}=0.005$ to 0.1 $\mathrm{s}^{-1}$, i.e., $400 \mathrm{~kJ} / \mathrm{mol}$. Because the temperatures used in the prior work lay above the solvus temperatures for $\gamma^{\prime}$ $(\sim 1123 \mathrm{~K})$ and $\gamma^{\prime \prime}(\sim 1200 \mathrm{~K})$, it can be surmised that the low value of $Q_{\text {app }}$ in Reference 49 was unaffected by interactions between dislocations and fine strengthening precipitates. The temperatures used in the present work, on the other hand, were lower, and thus dislocation-precipitate interactions may have indeed influenced plastic flow through various strengthening mechanisms or the development of back stresses which have been well documented in the creep literature for 718. ${ }^{[47,50,51]}$ An understanding of such possibilities was obtained from simulations of precipitation during heating of the ST samples, which are discussed later in this section.

The $\ln \dot{\varepsilon}-v s-1 / T$ curves for 718 STA samples (Figure 14(b)) revealed an approximately bilinear trend with a gradual change in slope at $\dot{\varepsilon} \sim 0.0025$ to $0.005 \mathrm{~s}^{-1}$ (ln $\dot{\varepsilon} \sim-5.3$ to -6 ). This apparently-unusual behavior may also have been a result of dislocation-precipitate interactions. It may be hypothesized that the steeper portion of each of the two results for STA samples (at lower temperatures and strain rates) was the signature of a decrease in back (threshold) stress with increasing temperature. In this regard, the data of Chaturvedi and $\mathrm{Han}^{[51]}$ for the steady-state creep of STA 718 with 27-nm $\gamma^{\prime \prime}$ precipitates indicated a decrease in back stress from $\sim 600$ to $450 \mathrm{MPa}$ when the temperature was increased from $873 \mathrm{~K}(1000 / T=1.15)$ to $943 \mathrm{~K}(1000 / T$ $=1.06)$. Simulations of precipitate dissolution described later in this section shed further light on this possibility. The higher-temperature/higher-strain-rate portion of the 718 STA data in Figure 14(b) exhibited a slope yielding an activation energy of the order of 400 to 500 $\mathrm{kJ} / \mathrm{mol}$ for both heating rates, in line with the high heating-rate result for the ST sample and the measurement of Zhou and Baker ${ }^{[49]}$ for $T \geq 1223 \mathrm{~K}[(1000 / T) \leq$ $0.818]$.
Simulations of precipitation and dissolution provided insight into the temperature regime for which dislocation-precipitate interactions might be most important. For all of the simulations, static values of the diffusivity of chromium ${ }^{[31]}$ were used because of the absence of quantitative information on the effect of concurrent straining on precipitation in 718 ; therefore the kinetics predictions were likely on the slow/sluggish side of actual behaviors. For ST samples, simulation predictions (Figure 15(a)) showed that volume fractions of $\sim 0.04$ of both $\gamma^{\prime \prime}$ and $\gamma^{\prime}$ are formed during heating at 75 $\mathrm{K} / \mathrm{min}$, followed by dissolution. The maximum diameters of the $\gamma^{\prime \prime}$ ellipsoids and $\gamma^{\prime}$ spheroids prior to onset of dissolution were 8 and $2 \mathrm{~nm}$, respectively. For the lower heating rate $\left(28 \mathrm{~K} / \mathrm{min}\right.$ ), noticeably-more $\gamma^{\prime \prime}$ (volume fraction $\sim 0.07)$, but with the same diameter $(8 \mathrm{~nm})$, was predicted. In contrast, the predicted volume fraction and size of $\gamma^{\prime}$ at the lower heating rate was relatively unchanged in comparison to that at the higher heating rate.

In the context of the precipitation predictions, the relatively low or high apparent activation energy for ST samples heated respectively at $75 \mathrm{~K} / \mathrm{min}$ or $28 \mathrm{~K} / \mathrm{min}$ (Figure 14(b)) appeared to correlate better with the amount (and temperature) of $\gamma^{\prime \prime}$ precipitation, and not with the very fine $\gamma^{\prime}$ particles. In particular, data in Figure 14(b) indicated an activation energy of $\sim 750$ $\mathrm{kJ} / \mathrm{mol}$ for ST samples heated at $28 \mathrm{~K} / \mathrm{min}$ and values of $1000 / T$ between 0.85 and 0.89 , or $\mathrm{T}$ between approximately 1125 and $1175 \mathrm{~K}$. This range is similar to the temperatures for which the $\gamma^{\prime \prime}$ fraction was predicted to exceed 0.05 , i.e., $1085 \mathrm{~K}$ to $1140 \mathrm{~K}$.

Simulation predictions of the dissolution of $\gamma^{\prime \prime}$ and $\gamma^{\prime}$ precipitates (each with an assumed initial average 3D diameter of $14 \mathrm{~nm}$, as deduced from 2D measurements) in 718 STA samples also provided a plausible correlation with the observed temperatures over which the activation energy transitioned from a higher to lower value. These simulations revealed that the majority of both phases dissolved at temperatures between 1100 and 


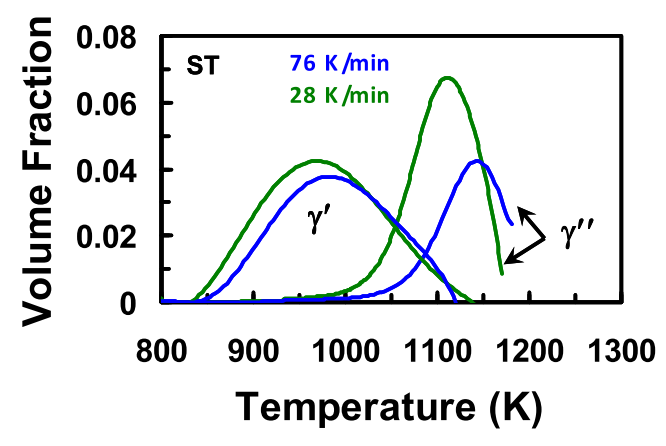

(a)

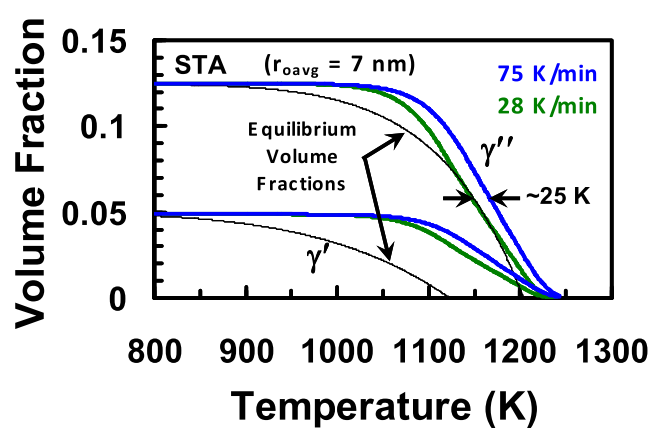

(b)

Fig. 15-Simulation predictions of precipitation and dissolution of $\gamma^{\prime \prime}$ and $\gamma^{\prime}$ during heating of superalloy 718 samples with (a) an ST initial condition or $(b)$ an STA initial condition.

$1200 \mathrm{~K}$ (Figure 15(b)). These temperatures bracketed the observed transition temperatures of $\sim 1176 \mathrm{~K}(1000 /$ $T=0.85)$ and $1149 \mathrm{~K}(1000 / T=0.87)$ for heating of STA samples at either 75 or $28 \mathrm{~K} / \mathrm{min}$, respectively (Figure 14(b)). Moreover, the difference in the observed transition temperatures for the two heating rates (1176 to $1149 \approx 25 \mathrm{~K}$ ), was very similar to the predicted retardation in dissolution when the heating rate was increased from 28 to $75 \mathrm{~K} / \mathrm{min}$ (Figure 15(b)). Last, the measured volume fraction of $\gamma^{\prime \prime}+\gamma^{\prime}$ precipitate $(\sim 0.069)$ in an STA 718 sample which fractured at $\sim 1200 \mathrm{~K}$ after being heated at a rate of $75 \mathrm{~K} / \mathrm{min}$ under a stress of $345 \mathrm{MPa}$ showed approximate agreement with the simulated value in Figure 15(b), i.e., $\sim 0.04$. The difference is likely associated with the effect of a finite cooling rate following fracture on re-growth of precipitates and/or measurement error.

Last, the strain rate sensitivity at temperatures at which $\gamma^{\prime \prime}$ and $\gamma^{\prime}$ would be expected to have dissolved (i.e., $T \geq 1150 \mathrm{~K}$ ) were determined from the $\ln \dot{\varepsilon}-v S-1 / T$ plots to be $\sim 0.13$ (ST) or $\sim 0.14$ (STA) (Table II). These $\mathrm{m}$ values correspond to a stress exponent of the strain rate $(n \sim 1 / m)$ of $\sim 7$, which is in approximate agreement with the n's determined by Chaturvedi and Han, ${ }^{[50,51]}$ i.e., 5 to 6 , at lower temperatures for which back-stress effects must be considered in modeling plastic flow.

\section{FUTURE OUTLOOK}

The present work has sought to introduce a new paradigm for quantifying the transient plastic flow response of metallic structural materials. This initial work has been based on uniaxial-tension behavior during deformation at an approximately constant true stress and constant heating rate. Based on these results, the following future research opportunities have been identified:

1. The present work was done with a screw-driven machine outfitted with a vacuum furnace that provided excellent axial temperature uniformity during concurrent heating and straining. Alternate test methods utilizing servohydraulic systems, induction heating, etc. may enable a broader range of test parameters as well as water quenching of specimens needed for detailed characterization of high-temperature microstructure evolution.

2. Constant-stress, constant-heating-rate tests performed in compression could be useful in providing data comparable to those generated herein, but without the occurrence of necking inherent in tension. Similarly, constant-stress, constant-cooling-rate tests in compression may be useful in the interpretation of various flow and fracture phenomena during non-isothermal hot forging. ${ }^{[52,53]}$

3. The formulation of nomograms summarizing the applied-stress and heating-rate dependence of the temperature at which plastic flow exceeds a certain specified level (e.g., 0.02 or 0.05 ) would be useful for system designers.

4. Additional work to quantify the "mechanical contribution" to the activation energy for the plastic flow of microstructures comprising two deforming phases would be useful in the basic understanding of constant-stress, constant-heating rate tests for titanium and other alloy systems.

5. Basic research to quantify the coupled evolution of an ensemble of precipitates and the accompanying back stress during continuous heating would help in the development of physics-based constitutive equations under transient conditions for superalloys such as 718. Such an effort would complement prior work relating microstructure evolution and constitutive response under non-isothermal creep conditions for $\gamma-\gamma^{\prime}$ superalloys. ${ }^{[54-56]}$

\section{SUMMARY AND CONCLUSIONS}

A mechanical test technique involving the application of a constant true stress during continuous heating at a constant rate was developed. This new method was validated for three types of metallic structural alloys consisting of a single phase (Ti-7Al), two deforming phases (Ti6242S), or a primary phase strengthened by an evolving dispersion of precipitates (superalloy 718). Measurements of the plastic strain $(\varepsilon)$ as a function of temperature $(T)$ and concomitant semilog $(\ln \dot{\varepsilon}-v s-1 / T)$ 
plots were used to determine the apparent activation energy $\left(Q_{\text {app }}\right)$ for hot deformation from individual tests as well as those conditions under which large (possibly undesirable) deformation may occur during service. From these observations, the following conclusions have been drawn for each of the three program alloys:

1. Linear semilog plots for Ti-7Al with a slope $\left(Q_{\text {app }} /\right.$ $R$ ) yielding an apparent activation energy of $\sim 250$ $\mathrm{kJ} / \mathrm{mol}$ suggest that the mechanism controlling transient plastic flow is similar to that for self-diffusion in $\alpha$ titanium.

2. Plots of $\ln \dot{\varepsilon}-v s-1 / T$ for Ti6242S with either a duplex (equiaxed/colony- $\alpha$ ) or fully-equiaxed structure are also linear but have slopes which indicate an apparent activation energy (410 to $450 \mathrm{~kJ} / \mathrm{mol}$ ) substantially greater than that for self diffusion or deformation of single-phase $\alpha$ or single-phase $\beta$. Models for the dissolution of equiaxed $\alpha$ during heating and the deformation of two-phase alloys indicate that the principal source of the high apparent activation energy for Ti6242S is a so-called "mechanical contribution", which was first proposed by Briottet and his co-workers to describe plastic flow under isothermal hot-working conditions.

3. Plots of $\ln \dot{\varepsilon}-v s-1 / T$ for superalloy 718 exhibit either a linear or a bilinear shape for initially solution-treated or solution-treated-and-aged material, respectively. Coupled with models of precipitation and/or dissolution during heating, these observations suggest that dislocation-precipitate interactions (e.g., the temperature dependence of back stresses) are the likely source of the observations.

\section{ACKNOWLEDGMENTS}

This work was conducted as part of the in-house research of the Air Force Research Laboratory's Materials and Manufacturing and Power and Propulsion Directorates. Technical discussions with M.G. Fahrmann, the experimental assistance of J.O. Brown and T.M. Brown, and provision of materials by ATI Specialty Materials, Flowserve, Haynes International, Inc., and Howmet Aerospace, are gratefully acknowledged.

\section{CONFLICT OF INTEREST}

On behalf of all authors, the corresponding author states that there is no conflict of interest.

\section{REFERENCES}

1. Handbook of Workability and Process Design, G.E. Dieter, H.A. Kuhn, and S.L. Semiatin, eds., ASM International, Materials Park, OH, 2003.

2. ASM Handbook, Vol. 8: Mechanical Testing and Evaluation, Tenth Edition, H.A. Kuhn and D. Medlin, eds., ASM International, Materials Park, OH, 2000.
3. A.M. Sabroff, F.W. Boulger, and H.J. Henning: Forging Materials and Practices, Rheinhold Book Company, New York, 1968.

4. T. Altan, F.W. Boulger, J.R. Becker, N. Akgerman, and H.J. Henning: Forging Equipment, Materials, and Practices, Report MCIC-HB-03, Metals and Ceramics Information Center, Battelle's Columbus Laboratories, Columbus, OH, 1973.

5. Quenching and Control of Distortion, H.E. Boyer and P.R. Cary, eds., ASM International, Materials Park, OH, 1988

6. S.S. Babu, N. Raghavan, J. Raplee, S.J. Foster, C. Frederick, M. Haines, S. Dinwiddie, M.K. Kirka, A. Plotkowski, Y. Lee, and R.R. Dehoff: Metall. Mater. Trans. A, 2018, vol. 49A, pp. 3764-80.

7. W.E. Frazier: J. Mater. Eng. Perf., 2014, vol. 24, pp. 1917-28.

8. L. Wang, M. Preuss, P.J. Withers, G. Baxter, and P. Wilson: Metall. Mater. Trans. B, 2005, vol. 36B, pp. 513-23.

9. L.B. Yang, J.-C. Gebelin, and R.C. Reed: Mater. Sci. Technol., 2011, vol. 27, pp. 1249-64.

10. D.W. Mahaffey, O.N. Senkov, R. Shivpuri, and S.L. Semiatin: Metall. Mater. Trans. A, 2016, vol. 47A, pp. 3981-4000.

11. D.J. Tung, D.W. Mahaffey, O.N. Senkov, S.L. Semiatin, and W. Zhang: Sci. Technol. Weld. Join., 2019, vol. 24, pp. 136-47.

12. P.G. Tucker and P.S. Keogh: Proc. Inst. Mech. Engrs., 1995, vol. 209, pp. 99-108.

13. F.R. DeJarnette, H.H. Hamilton, K.J. Weilmuenster, and F.M. Cheatwood: J. Thermophys., 1987, vol. 1, pp. 5-12.

14. D. Knight, O. Chazot, J. Austin, M.A. Badr, G. Candler, B. Celik, D. de Rosa, R. Donelli, J. Komives, A. Lani, D. Levin, I. Nompelis, M. Panesi, G. Pezzella, B. Reimann, O. Tumuklug, and K. Yuceil: Prog. Aerospace Sci., 2017, vol. 90, pp. 39-53.

15. P.D. Nicolaou, R.E. Bailey, and S.L. Semiatin: in Handbook of Workability and Process Design, G.E. Dieter, H.A. Kuhn, and S.L. Semiatin, eds., ASM International, Materials Park, OH, 2003, pp. 68-85.

16. H.G. Suzuki and D. Eylon: Mater. Sci. Eng. A, 1998, vol. A243, pp. 126-33.

17. F.F. Noecker II and J.N. DuPont: Welding J., 2009, vol. 88 (\#1), pp. $7 \mathrm{~s}-20 \mathrm{~s}$

18. S. Shi, J.C. Lippold, and J. Ramirez: Welding J., 2010, vol. 89 (\#10), pp. 210s-17s

19. S.S. Babu, J. Livingston, and J.C. Lippold: Metall. Mater. Trans. $A$, 2013, vol. 44, pp. 3577-91.

20. M. Saby, E. Massoni, and N. Bozzolo: Mater. Charact., 2014, vol. 89 , pp. 88-92.

21. S. Tabaie, D. Shahriari, C. Plouze, A. Devaux, J. Cormier, and M. Jahazi: Mater. Sci. Eng. A, 2019, vol. A766, paper 138391.

22. A. Constantinescu, A. Charkaluk, G. Lederer, and L. Verger: Inter. J. Fatigue, 2004, vol. 26, pp. 805-818.

23. H. Sehitoglu: in Advances in Fatigue Lifetime Predictive Techniques, ASTM STP 1122, M. R. Mitchell and R.W. Landgraf, eds., American Society for Testing and Materials, Philadelphia, 1992, pp. 47-76.

24. J. Cormier, M. Jouiad, F. Hamon, P. Villechaise, and X. Milhet: Philos. Mag. Ltrs., 2010, vol. 90 (\#8), pp. 611-20.

25. J. Cormier: in Superalloys 2016, M. Hardy, E. Huron, U. Glatzel, B. Griffin, B. Lewis, C. Rae, V. Seetharaman, and S. Tin, eds., TMS, Warrandale, PA, 2016, pp. 385-94.

26. S.L. Semiatin, N.C. Levkulich, C.A. Heck, A.E. Mann, N. Bozzolo, A.L. Pilchak, and J.S. Tiley: Metall. Mater. Trans. A, 2020, vol. 51A, pp. 2291-305.

27. S.L. Semiatin, N.C. Levkulich, R. Larsen, J.S. Tiley, K.N. Wertz, F. Zhang, T.M. Smith, R.Y. Zhang, H.B. Dong, P. Gadaud, and J. Cormier: Metall. Mater. Trans. A, 2021, vol. 52A, pp. 3706-26.

28. S.L. Semiatin and G.A. Sargent: Key Eng. Mater., 2010, vol. 433, pp. 235-40.

29. S.L. Semiatin and J.J. Jonas: Formability and Workability of Metals: Plastic Instability and Flow Localization, American Society for Metals, Metals Park, OH, 1984.

30. A.K. Ghosh and R.A. Ayres: Metall. Trans. A, 1976, vol. 7A, pp. $1589-91$

31. S.L. Semiatin, J.S. Tiley, F. Zhang, T.M. Smith, R.Y. Zhang, H.B. Dong, P. Gadaud, and J. Cormier: Metall. Mater. Trans. A, 2021, vol. 52A, pp. 483-99.

32. Y. Mishin and C. Herzig: Acta Mater., 2000, vol. 48, pp. 589-623.

33. H. Oikawa and T. Oomori: Mater. Sci. Eng. A, 1988, vol. A104, pp. 125-30. 
34. S.L. Semiatin, N.C. Levkulich, A.A. Salem, and A.L. Pilchak: Metall. Mater. Trans. A, 2020, vol. 51A, pp. 4695-710.

35. H. Araki, T. Yamane, Y. Minamino, S. Saji, Y. Hana, and S.B. Jung: Metall. Mater. Trans. A, 1994, vol. 25A, pp. 874-76.

36. H. Oikawa, Y. Ishikawa, and M. Seki: in Titanium '92: Science and Technology, F.H. Froes and I. Caplan, eds., TMS, Warrendale, PA, 1993, pp. 1779-1786.

37. H. Oikawa, K. Nishimura, and M.X. Cui: Scripta Metall., 1985, vol. 19, pp. 825-28.

38. P. Dadras and J.F. Thomas, Jr: Metall. Trans. A, 1981, vol. 12A, pp. 1867-76.

39. S.L. Semiatin and G.D. Lahoti: Metall. Trans. A, 1981, vol. 12A, pp. 1705-1717.

40. L. Briottet, J.J. Jonas, and F. Montheillet: Acta Mater., 1996, vol. 44, pp. 1665-72.

41. S.L. Semiatin, F. Montheillet, G. Shen, and J.J. Jonas: Metall. Mater. Trans. A, 2002, vol. 33A, pp. 2719-27.

42. P. Vo, M. Jahazi, S. Yue, and P. Bocher: Mater. Sci. Eng. A, 2007, vol. A447, pp. 99-110.

43. M. Kulakov, S. Rahimi, and S.L. Semiatin: Metall. Mater. Trans. $A, 2021$, vol. 52A, in press.

44. S.L. Semiatin, T.M. Lehner, J.D. Miller, R.D. Doherty, and D.U. Furrer: Metall. Mater. Trans. A, 2007, vol. 38A, pp. 910-21.

45. J.M. Oblak, D.F. Paulonis, and D.S. Duvall: Metall. Trans. A, 1974, vol. 5, pp. 143-53.

46. M.C. Chaturvedi and Y.F. Han: Metal Sci., 1983, vol. 17, pp. $145-49$.
47. A. Drexler, A. Fischersworring-Bunk, B. Oberwinkler, W. Ecker, and H.-P. Gänser: Int. J. Plasticity, 2018, vol. 105, pp. 62-73.

48. S. Zhang, X. Lin, L. Wang, X. Yu, Y. Hu, H. Yang, L. Lei, and W. Huang: Mater. Sci. Eng. A, 2021, vol. A812, paper 141145, pp. $1-11$.

49. L.X. Zhou and T.N. Baker: Mater. Sci. Eng. A, 1994, vol. A177, pp. $1-9$.

50. M.C. Chaturvedi and Y.F. Han: Mater. Sci. Eng., 1987, vol. 89, pp. 25-33.

51. M.C. Chaturvedi and Y.F. Han: in Superalloy $718-$ Metallurgy and Applications, E.A. Loria, ed., TMS, Warrendale, PA, 1989, pp. 489-98.

52. G. Shen, S.L. Semiatin, and T. Altan: J. Mater. Proc. Technol., 1993, vol. 36, pp. 303-19.

53. J. Mao, K.M. Chang, V.L. Keefer, and D. Furrer: J. Mater. Eng. Perform., 2000, vol. 9 (2), pp. 204-14.

54. J. Cormier and G. Cailletaud: Mater. Sci. Eng. A, 2010, vol. A527, pp. $6300-312$.

55. R. Giraud, Z. Hervier, J. Cormier, G. Saint-Martin, F. Hamon, X. Milhet, and J. Mendez: Metall. Mater. Trans. A, 2013, vol. 44A, pp. 131-46.

56. J.-B. le Graverend, J. Cormier, F. Gallerneau, P. Villechaise, S. Kruch, and J. Mendez: Int. J. Plasticity, 2014, vol. 59, pp. 55-83.

Publisher's Note Springer Nature remains neutral with regard to jurisdictional claims in published maps and institutional affiliations. 